\title{
Survival outcomes for patients with surgically induced end-stage renal disease
}

\author{
Bimal Bhindi ${ }^{1,2}$; Dennis Asante ${ }^{3}$; Megan E. Branda ${ }^{3}$; LaTonya J. Hickson ${ }^{4,5}$; Ross J. Mason ${ }^{1}$;
} Molly M. Jeffery ${ }^{3}$; Stephen A. Boorjian ${ }^{1}$; Bradley C. Leibovich ${ }^{1}$; R. Houston Thompson ${ }^{1}$

${ }^{1}$ Department of Urology, Mayo Clinic, Rochester, MN, United States; ${ }^{2}$ Section of Urology, Department of Surgery, University of Calgary, Calgary, AB, Canada; ${ }^{3}$ Department of Health Services Research, Mayo Clinic, Rochester, MN, United States; ${ }^{4}$ Division of Nephrology and Hypertension, Department of Medicine, Mayo Clinic, Rochester, MN, United States; ${ }^{5}$ Center for the Science of Health Care Delivery, Mayo Clinic, Rochester, MN, United States

Acknowledgments/Funding: LJH is supported by Satellite Healthcare, a not-for-profit renal care provider and a National Institute of Diabetes and Digestive and Kidney Diseases of the National Institute of Health grant K23 DK109134. The data reported here have been supplied by the United States Renal Data System (USRDS). The interpretation and reporting of these data are the responsibility of the author(s) and in no way should be seen as an official policy or interpretation of the U.S. government.

Cite as: Can Urol Assoc J 2019 September 27; Epub ahead of print. http://dx.doi.org/10.5489/cuaj.6010

Published online September 27, 2019

$* * *$

\section{Abstract}

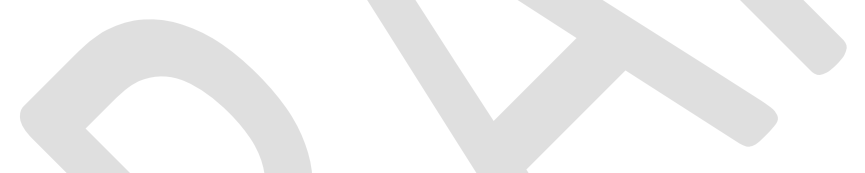

Introduction: While medically induced end-stage renal disease (m-ESRD) has been wellstudied, outcomes in patients with surgically induced ESRD (s-ESRD) are unknown. We sought to quantitatively compare the non-oncological outcomes for s-ESRD and m-ESRD in a large population-based cohort.

Methods: Medicare patients >65 years old initiating hemodialysis were identified using the U.S. Renal Data System database (2000-2012). Metastatic cancer, prior transplant history, and nephrectomy for polycystic kidney disease were exclusion criteria. Patients were classified as having s-ESRD or m-ESRD based on hospital and physician claims for nephrectomy within a year preceding the onset of maintenance hemodialysis. Outcomes included non-cancer mortality (NCM), overall survival (OS), cardiovascular event (CVE), and renal transplantation. Time-toevent analyses were performed using Kaplan-Meier and cumulative incidence curves, and multivariable Cox and Fine-and-Grey regression models.

Results: The cohort included 312612 patients, of whom 1648 (0.53\%) had s-ESRD. Compared to m-ESRD patients, s-ESRD patients had a significantly lower five-year cumulative incidence of NCM (68\% vs. 80\%; $<<0.001)$ and CVE (62\% vs. 68\%; $<<0.001)$, with a correspondingly higher probability of OS (22\% vs. $17 \%$; $\mathrm{p}<0.001)$ and rate of renal transplantation (3.6\% vs. 
2.0\%; $\mathrm{p}<0.001)$. On multivariable analyses, s-ESRD remained associated with lower risks of NCM $(p<0.001)$ and CVE $(p<0.001)$, improved OS $(\mathrm{p}<0.001)$, and higher chance of renal transplantation $(\mathrm{p}<0.001)$.

Conclusions: While outcomes for s-ESRD appear more favorable than m-ESRD, s-ESRD is still associated with a substantial risk of NCM and CVE, and a low incidence of renal transplantation in Medicare patients $>65$ years old. These non-oncological outcomes are worth considering in patients potentially facing postoperative ESRD.

\section{Introduction}

Dialysis for end-stage renal disease (ESRD) is associated with significant morbidity and risk of mortality. Despite improvements over time, estimated 3-year survival on hemodialysis is 57\%, a striking difference from the estimated 97\% 3-year survival in age and sex-matched controls in the general population. ${ }^{1}$ In order to avoid dialysis, nephron-sparing surgery is recommended for patients with bilateral renal tumors and for patients with a tumor in a solitary kidney. ${ }^{2,3}$ Furthermore, there is an increasing drive to perform nephron-sparing surgery in all patients in order to maximize post-operative renal function. The benefit of renal preservation is realized beyond facilitation of uremic toxin clearance as reductions in in glomerular filtration rate (GFR) are associated with increased risk of hospitalization, cardiovascular events, and death., ${ }^{4,5}$

Interestingly, relatively recent data suggests that not all etiologies of chronic kidney disease (CKD) are the same. Conditions leading to intrinsic renal dysfunction either abruptly or over time are deemed medically-induced. In contrast, surgically-induced CKD appears to have a lower risk of progressive renal decline and mortality compared to patients with medicallyinduced CKD. ${ }^{6,7}$

Medically-induced ESRD (m-ESRD), representing that largest subset of the ESRD population, comprises the basis for reports on survival outcomes in dialysis studies. ${ }^{8}$ Thus, survival outcomes of patients with surgically-induced ESRD (s-ESRD), and how these outcomes differ from patients with medically-induced ESRD, remain poorly characterized. There are several instances when surgeons need to balance adequate oncologic control against nephronsparing. As such, we sought to characterize and quantitatively compare the non-oncologic outcomes for s-ESRD to m-ESRD in a large population-based cohort.

\section{Methods}

\section{Design and participants}

The United States Renal Data System (USRDS) is a national data system funded by the National Institute of Diabetes and Digestive and Kidney Diseases (NIDDK) that collects data on patients with CKD and ESRD. The data originate from the Centers for Medicare and Medicaid Services (CMS), the Organ Procurement and Transplantation Network (OPTN), the Centers for Disease 
Control and Prevention (CDC), the ESRD Networks, the USRDS Special Studies, and the U.S. Census. Data have been collected on both Medicare enrollees and other patients of all ages since 1995, when the Medical Evidence Report forms (CMS-2728) became mandatory for providers to complete for all ESRD patients. ${ }^{9,10}$

Using the USRDS, we completed a retrospective cohort study of patients 66 years of age or older who initiated maintenance hemodialysis, defined as at least 90 days, between 1/1/2000 and 12/31/2012. We included only patients who started with center hemodialysis and had Medicare as their primary coverage from the start of their dialysis. To allow uniform assessment of co-morbidities, we further restricted the cohort to those with Medicare coverage for the 12 months preceding the onset of hemodialysis. Patients with renal transplantation prior to the start of dialysis or a history of metastatic cancer were excluded. In the s-ESRD group, patients with a history of polycystic kidney disease were also excluded because we were unable to determine if ESRD preceded a nephrectomy that was done in preparation for renal transplantation (Supplementary Fig. 1).

\section{Exposure, covariates, and outcomes}

To classify patients as having s-ESRD, we adapted an externally validated claims-based algorithm for identifying patients who underwent renal cancer surgery. ${ }^{11}$ S-ESRD patients had an inpatient claim for kidney cancer surgery identified using International Classification of Diseases, 9th Revision, Clinical Modification (ICD-9-CM) procedure codes and an associated ICD-9 diagnosis code for a renal or upper tract urothelial neoplasm within 12 months before initiating chronic hemodialysis (Appendix). Patients not satisfying this definition were classified as having m-ESRD.

Baseline co-morbidities were identified using ICD-9-CM codes through the USRDS claims data for the 12 months preceding the initiation of chronic dialysis.

The primary outcome of interest was non-cancer mortality (NCM), using the date of death on the CMS-2728 form. Data on cause of death has been previously validated. ${ }^{10,12}$ In the main analysis, patients with an unknown cause of death were counted as non-cancer deaths. A sensitivity analysis was performed excluding patients with an unknown cause of death in order to ensure this a-priori decision did not introduce bias.

Secondary outcomes were overall survival (OS), occurrence of a cardiovascular event (CVE; including acute myocardial infarction, cerebrovascular accident, sudden cardiac death, and peripheral vascular event; see Appendix), hospitalization (any cause), and receipt of a renal transplant. These outcomes were identified using USRDS medical claims data including ICD-9CM procedures and Current Procedural Terminology (CPT). Hospitalizations were identified using inpatient claims data. Outcomes were assessed starting from 90 days after the initiation of hemodialysis to avoid the inclusion of patients requiring temporary hemodialysis. Patients were followed until death or censorship due to loss to follow-up or receipt of a renal transplant (except in the analysis where renal transplant was the outcome of interest). 


\section{Statistical analysis}

Kaplan-Meier curves were used to plot the estimated survival function for up to 10 years of follow-up and multivariable Cox proportional hazards models were performed to compare OS between groups. Cumulative incidence curves and multivariable Fine-and-Grey competing risks models were used to compare the remainder of the outcomes between groups. Multivariable models were adjusted for age at first ESRD service (5-yr groups), gender, race, Charlson comorbidity index, and history of myocardial infarction, cerebrovascular disease, diabetes (type I and II), hypertension, and dyslipidemia. A conditional frailty model was used to assess recurrent hospitalizations, using random effects to model hospitalizations as multiple non-independent events for each patient. All assumptions for models were verified and multicollinearity was assessed (Variance Inflation Factor $<10$ ).

In order to test our a-priori decision to use a 12 months interval from surgery to dialysis for inclusion in the s-ESRD group, we performed a sensitivity analysis using a tighter time interval whereby we excluded those whose interval from surgery to dialysis was greater than 2 months.

Statistical analyses were performed using SAS version 9.4 (SAS Institute, Cary, NC) and $\mathrm{R}$ version 3.2.3 (R Foundation for Statistical Computing, Vienna, Austria). All tests were twosided and p-values $<0.05$ were considered statistically significant.

\section{Results}

The final cohort included 312,612 patients, of whom 1,648 (0.53\%) had s-ESRD (Supplementary Fig. 1). Patient demographics and baseline co-morbidities are summarized in Table 1. Mean age for patients with s-ESRD and m-ESRD was 74.4 years $(S D=5.7)$ and 75.9 years $(S D=6.5)$, respectively, and median Charlson co-morbidity index was 8 (range:1-15) and 7 (range:0-17), respectively. Notably, patients in the m-ESRD group were more likely to have a history of myocardial infarction (26.2\% vs. 22.5\%), cerebrovascular disease (36.4\% vs. 33.9\%), and diabetes (71.0\% vs. 57.1\%), while patients with s-ESRD were more likely to have a history of kidney cancer (89.3\% vs. 3.5\%) or other cancer (33.1\% vs. 16.2\%)(Table 1). Median time from surgery to dialysis in the s-ESRD group was 18 days (IQR 4,151). The median follow-up among those alive at last follow-up was 2.8 years (IQR 1.5,4.8) and 2.3 years (IQR 1.2,4.0) in the sESRD and m-ESRD groups, respectively.

\section{Survival outcomes}

There were a total of 274,769 deaths recorded, of which 9,115 were cancer-related deaths and 210,090 were non-cancer deaths, while 54,745 patients had an unknown cause of death. OS at 1 , 5 , and 10 years from the initiation of maintenance dialysis was $79 \%, 22 \%$, and $3 \%$, respectively, in the s-ESRD group versus 74\%, 17\%, and 1\%, respectively, in the m-ESRD group (Fig. 1a). In the multivariable Cox regression analysis (Table 2), s-ESRD was associated with improved OS $(\mathrm{HR}=0.76 ; 95 \% \mathrm{CI} 0.72-0.80 ; \mathrm{p}<0.001)$ compared to m-ESRD, after adjusting for age, race, 
Charlson co-morbidity index, and history of myocardial infarction, cerebrovascular disease, diabetes, hypertension, and dyslipidemia.

Meanwhile, the cumulative incidence of non-cancer mortality at 1, 5, and 10 years from the initiation of maintenance dialysis was $18 \%, 68 \%$, and $86 \%$, respectively, in the s-ESRD group and 25\%, 80\%, and 95\%, respectively, in the m-ESRD group (Fig. 1b). At the same time, the cumulative incidences of cancer mortality at 1, 5, and 10 years were $3 \%, 10 \%$, and $11 \%$, respectively, in the s-ESRD group and 1\%, 3\%, and 3\%, respectively, in the m-ESRD group (Fig. 1b). In the multivariable competing risks analyses (Table 2), s-ESRD versus m-ESRD was associated with a lower risk of non-cancer mortality (HR=0.62;95\%CI 0.59-0.67;p<0.001). A sensitivity analysis excluding patients with an unknown cause of death did not meaningfully alter findings (data not shown).

\section{Cardiovascular events}

During follow-up, there were 209,984 patients who had a CVE. The cumulative incidence of having a CVE at 1, 5, and 10-years from the initiation of maintenance dialysis was 35\%, $62 \%$, and $66 \%$, respectively, in the s-ESRD group, and $41 \%, 68 \%$, and $71 \%$, respectively, in the mESRD group (Fig. 2a). In the multivariable competing risks analyses (Table 2), s-ESRD versus m-ESRD remained associated with a lower risk of having a CVE (HR=0.85;95\%CI 0.80$0.91 ; \mathrm{p}<0.001)$.

\section{Hospitalizations}

During follow-up, 1521 patients in the s-ESRD group were hospitalized a median of 4 times (IQR 2,8) and 282,701 patients in the m-ESRD group $\quad$ were hospitalized a median of 4 times (IQR 2,7). The cumulative incidence of ever being hospitalized at 6 months, 1 year, and 5 years from the initiation of maintenance dialysis was 52\%, 69\%, and 93\%, respectively, in the sESRD group, and 51\%, 68\%, and 92\%, respectively, in the m-ESRD group (Fig. 2b). In the multivariable competing risks analyses (Table 2), there was no significant difference in the risk of ever being hospitalized between s-ESRD and m-ESRD (HR=0.99;95\%CI 0.94-1.04;p=0.77). However, in the frailty model analysis allowing for recurrent events, s-ESRD was associated with a lower risk of hospitalizations during follow-up (HR=0.89; 95\%CI 0.86-0.92; $<0.001)$.

\section{Renal transplantation}

During follow-up, 6,402 patients underwent renal transplantation. The cumulative incidence of renal transplantation at 5 and 10 years from the initiation of maintenance dialysis was $3.6 \%$ and $4.0 \%$, respectively, in the s-ESRD group, and $2.0 \%$ and $2.1 \%$, respectively in the m-ESRD group (Fig. 2c). In the multivariable competing risks analyses (Table 2), s-ESRD versus m-ESRD was associated with a greater chance of receiving a renal transplant $(\mathrm{HR}=1.63$; 95\%CI 1.26-2.10; $\mathrm{p}<0.001$ ).

\section{Sensitivity analysis}


In the sensitivity analysis that only included patients in the s-ESRD if they initiated dialysis within 2 months of surgery, effect estimates from the multivariable models were not meaningfully different (Supplementary Table 1).

\section{Discussion}

S-ESRD is associated with longer OS, a lower risk of non-cancer mortality, a lower risk of CVE, a lower rate of recurring hospitalizations (although the risk of ever being hospitalized was not significantly different), and a greater chance of receiving a renal transplant when compared to mESRD. However, outcomes are still poor with s-ESRD, with a $78 \%$ probability of mortality, a $68 \%$ probability of non-cancer mortality that surpasses the cancer-mortality risk, and only a $4 \%$ probability of renal transplant at 5 years.

These data have important implications for patients with a renal tumor in a solitary functioning kidney and prognostication for individuals facing ESRD after surgical intervention. Assuming nephron sparing is not possible, realistic expectations should be set, including the low likelihood of transplantation. Of note, the low probability of transplantation is consistent with our institutional series where only $4 / 27$ patients (15\%) surgically rendered anephric were able to receive a renal transplant. ${ }^{13}$

Strengths of this study include its size, the population-based design, which enhances the generalizability of these findings, and the relative completeness of follow-up, with the majority of patients being followed until death.

While the adverse effects of diminished renal function were initially established in a population with largely medical etiologies of CKD, ${ }^{4,5}$ it has been confirmed that nephrectomyinduced CKD is also associated with increased risk of subsequent cardiovascular morbidity and mortality, ${ }^{14,15}$ as well as all-cause mortality. ${ }^{14,16}$

Notably, however, differences between surgical and medical CKD have been described. ${ }^{6,7}$ Lane et al. ${ }^{6}$ found a slower rate of GFR decline (0.7\% vs. $\left.4.7 \%\right)$ in the surgical CKD group versus medical CKD group. This makes intuitive sense given the one-time surgical insult versus the ongoing insult of the medical comorbidities on renal function. ${ }^{17}$ Given that the most common cause of CKD and ESRD is diabetes, outcomes in medical CKD are likely worsened by the end-organ effects of this systemic disease.

Moreover, survival outcomes in patients with surgically-induced CKD more closely approximate those of patients without CKD rather than those with medical-surgical CKD. ${ }^{6}$ Specifically, Lane et al. ${ }^{6}$ reported that non-cancer mortality at 5 years was $6 \%$ in patients without CKD, $9 \%$ in patients with surgical CKD, and 20\% in patients with medical-surgical CKD. These data are consistent with the European Organisation for Research and Treatment of Cancer (EORTC)-30904 randomized trial comparing survival outcomes between radical and partial nephrectomy. ${ }^{18}$ Despite superior renal function outcomes after partial nephrectomy, ${ }^{19}$ this did not translate into a survival benefit. 
On the other hand, one study ${ }^{20}$ suggests that it may in part depend on the new postoperative baseline eGFR that is achieved. Lane et al. ${ }^{20}$ reported that a postoperative baseline eGFR less than $45 \mathrm{ml} / \mathrm{min} / 1.73 \mathrm{~m}^{2}$ was associated with a greater risk of progressive renal decline, perhaps due to hyperfiltration injury, ${ }^{21,22}$ and all-cause mortality.

The data in the present study represent the extreme situation whereby postoperative ESRD is surgically induced. Consistent with this notion, we found poor survival outcomes in the s-ESRD group, albeit slightly superior to the m-ESRD group.

Similarly, outcomes differences exist within the m-ESRD populations. O’Shaughnessy et al. $^{23}$ recently showed variations in CVE rates between those with glomerulonephritis-induced and diabetes-ESRD. The risk of CVE was substantially higher for diabetes-ESRD (adjusted $\mathrm{HR}=2.97,95 \%$ CI 2.77-3.20) compared to IgA nephropathy. This difference may be due to the multi-system effects and duration of the underlying medical causes of ESRD in the m-ESRD group, particularly in diabetes. ${ }^{24,25}$ However, in our study, the observed survival difference between s-ESRD and m-ESRD was preserved after adjusting for diabetes and other important clinical factors.

There are several limitations worth mentioning. First, in order to use a Medicare claimsbased definition for s-ESRD, we were limited to analyzing patients $>65$ years old and it is unknown how our findings apply to younger patients. We considered using the cause of ESRD data provided on the CMS-2728 form in order to classify s-ESRD versus m-ESRD status, but this field did not demonstrate satisfactory validity when compared to the claims-based standard (data not shown). Second, we did not have data on the indication for nephrectomy or disease severity, although $89 \%$ of patients in the s-ESRD group had a kidney cancer diagnosis. Third, we were unable to differentiate the specific site of fatal cancer. Given the low rates of background cancer mortality in the m-ESRD group, it is likely that most cancer mortalities in the s-ESRD were related to kidney cancer or upper tract urothelial cancer. Fourth, we did not have access to a comparison group who underwent nephrectomy but did not develop ESRD. Finally, we did not have preoperative renal function data or data on whether patients had a solitary kidney. As such, we cannot rule out the presence of concurrent medical renal disease in the s-ESRD group. However, if present, this would bias the results towards the null by making the groups more similar, and therefore our estimates are likely on the conservative side.

\section{Conclusions}

Surgically-induced ESRD is associated with a more favorable OS, lower risks of non-cancer mortality, CVE, and hospitalizations, and a greater chance of receiving a renal transplant compared relatively to m-ESRD_in Medicare patients $>65$ years old. However, the outcomes are still poor with s-ESRD, with the non-cancer mortality risk eclipsing the cancer-related mortality risk. These non-oncologic outcomes are worth considering in patients potentially facing s-ESRD. 


\section{References}

1. Saran R, Robinson B, Abbott KC, et al. US Renal Data System 2017 Annual Data Report: Epidemiology of Kidney Disease in the United States. Am J Kidney Dis 2018;71(3S1):A7.

2. Lerner SE, Hawkins CA, Blute ML, et al. Disease outcome in patients with low stage renal cell carcinoma treated with nephron sparing or radical surgery. 1996. J Urol 2002;167(2 Pt 2):884-889; discussion 889-890.

3. Novick AC, Streem S, Montie JE, et al. Conservative surgery for renal cell carcinoma: a single-center experience with 100 patients. 1989. J Urol 2002;167(2 Pt 2):878-882; discussion 883.

4. Go AS, Chertow GM, Fan D, et al. Chronic kidney disease and the risks of death, cardiovascular events, and hospitalization. N Engl J Med 2004;351(13):1296-1305.

5. Matsushita K, Mahmoodi BK, Woodward M, et al. Comparison of risk prediction using the CKD-EPI equation and the MDRD study equation for estimated glomerular filtration rate. JAMA 2012;307(18):1941-1951.

6. Lane BR, Campbell SC, Demirjian S, et al. Surgically induced chronic kidney disease may be associated with a lower risk of progression and mortality than medical chronic kidney disease. J Urol 2013;189(5):1649-1655.

7. Demirjian S, Lane BR, Derweesh IH, et al. Chronic kidney disease due to surgical removal of nephrons: relative rates of progression and survival. J Urol 2014;192(4):10571062.

8. Mailloux LU, Bellucci AG, Napolitano B, et al. Survival estimates for 683 patients starting dialysis from 1970 through 1989: identification of risk factors for survival. Clin Nephrol 1994;42(2):127-135.

9. US Renal Data System. 2015 Researcher's Guide to the USRDS Database. National Institutes of Health, National Institute of Diabetes and Digestive and Kidney Diseases. https://www.usrds.org/research.aspx. Published 2015. Accessed 1/31/2018.

10. Foley RN, Collins AJ. The USRDS: what you need to know about what it can and can't tell us about ESRD. Clin J Am Soc Nephrol 2013;8(5):845-851.

11. Miller DC, Saigal CS, Warren JL, et al. External validation of a claims-based algorithm for classifying kidney-cancer surgeries. BMC Health Serv Res 2009;9:92.

12. Rocco MV, Yan G, Gassman J, et al. Comparison of causes of death using HEMO Study and HCFA end-stage renal disease death notification classification systems. The National Institutes of Health-funded Hemodialysis. Health Care Financing Administration. Am J Kidney Dis 2002;39(1):146-153.

13. Boswell TC, Sharma V, Westerman ME, et al. Frequency and Predictors of Renal Transplantation Among Patients Rendered Surgically Anephric for Sporadic Renal Cancer. Urology 2019.

14. Weight CJ, Larson BT, Fergany AF, et al. Nephrectomy induced chronic renal insufficiency is associated with increased risk of cardiovascular death and death from any cause in patients with localized cT1b renal masses. J Urol 2010;183(4):1317-1323.

15. Miller DC, Schonlau M, Litwin MS, et al. Renal and cardiovascular morbidity after partial or radical nephrectomy. Cancer 2008;112(3):511-520. 
16. Kaushik D, Kim SP, Childs MA, et al. Overall survival and development of stage IV chronic kidney disease in patients undergoing partial and radical nephrectomy for benign renal tumors. Eur Urol 2013;64(4):600-606.

17. Lane BR, Demirjian S, Derweesh IH, et al. Is all chronic kidney disease created equal? Curr Opin Urol 2014;24(2):127-134.

18. Van Poppel H, Da Pozzo L, Albrecht W, et al. A prospective, randomised EORTC intergroup phase 3 study comparing the oncologic outcome of elective nephron-sparing surgery and radical nephrectomy for low-stage renal cell carcinoma. Eur Urol 2011;59(4):543-552.

19. Scosyrev E, Messing EM, Sylvester R, et al. Renal function after nephron-sparing surgery versus radical nephrectomy: results from EORTC randomized trial 30904. Eur Urol 2014;65(2):372-377.

20. Lane BR, Demirjian S, Derweesh IH, et al. Survival and Functional Stability in Chronic Kidney Disease Due to Surgical Removal of Nephrons: Importance of the New Baseline Glomerular Filtration Rate. Eur Urol 2015;68(6):996-1003.

21. Helal I, Fick-Brosnahan GM, Reed-Gitomer B, et al. Glomerular hyperfiltration: definitions, mechanisms and clinical implications. Nat Rev Nephrol 2012;8(5):293-300.

22. Hostetter TH. Hyperfiltration and glomerulosclerosis. Semin Nephrol 2003;23(2):194199.

23. O'Shaughnessy MM, Liu S, Montez-Rath ME, et al. Cause of kidney disease and cardiovascular events in a national cohort of US patients with end-stage renal disease on dialysis: a retrospective analysis. Eur Heart J 2018.

24. Squadrito G, Cucinotta D. The late complications of diabetes mellitus. Ann Ital Med Int 1991;6(1 Pt 2):126-136.

25. Clements RS, Jr., Bell DS. Complications of diabetes. Prevalence, detection, current treatment, and prognosis. The American journal of medicine 1985;79(5A):2-7.

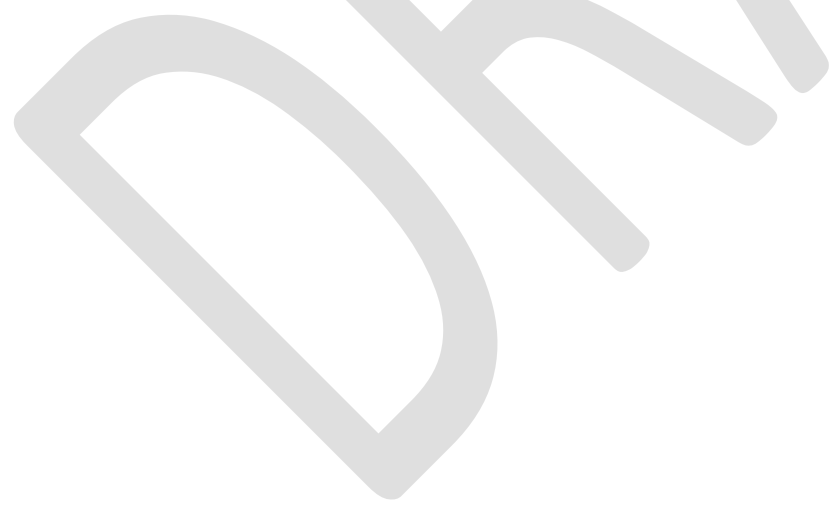




\section{Figures and Tables}

Fig. 1. Comparison of (A) overall survival; (B) non-cancer mortality, and cancer-related mortality between patients with surgically and medically-induced end-stage renal disease. $\mathrm{m}$ ESRD: medically-induced end-stage renal disease; s-ESRD: surgically induced end-stage renal disease.

A
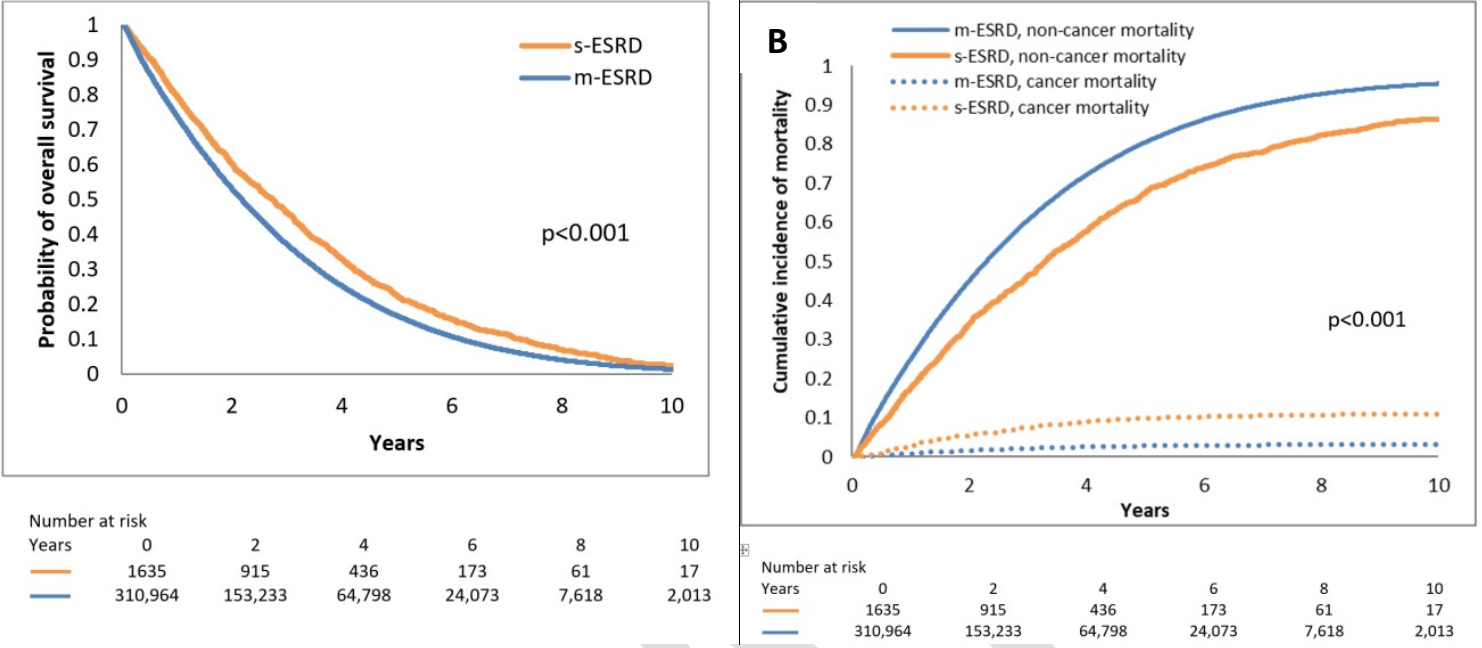
Fig. 2. Cumulative incidence of (A) cardiovascular events; $(\boldsymbol{B})$ hospitalization; and $(\boldsymbol{C})$ renal transplantation. Counts <11 suppressed as per USRDS policy. m-ESRD: medically-induced endstage renal disease; s-ESRD: surgically induced end-stage renal disease.

A
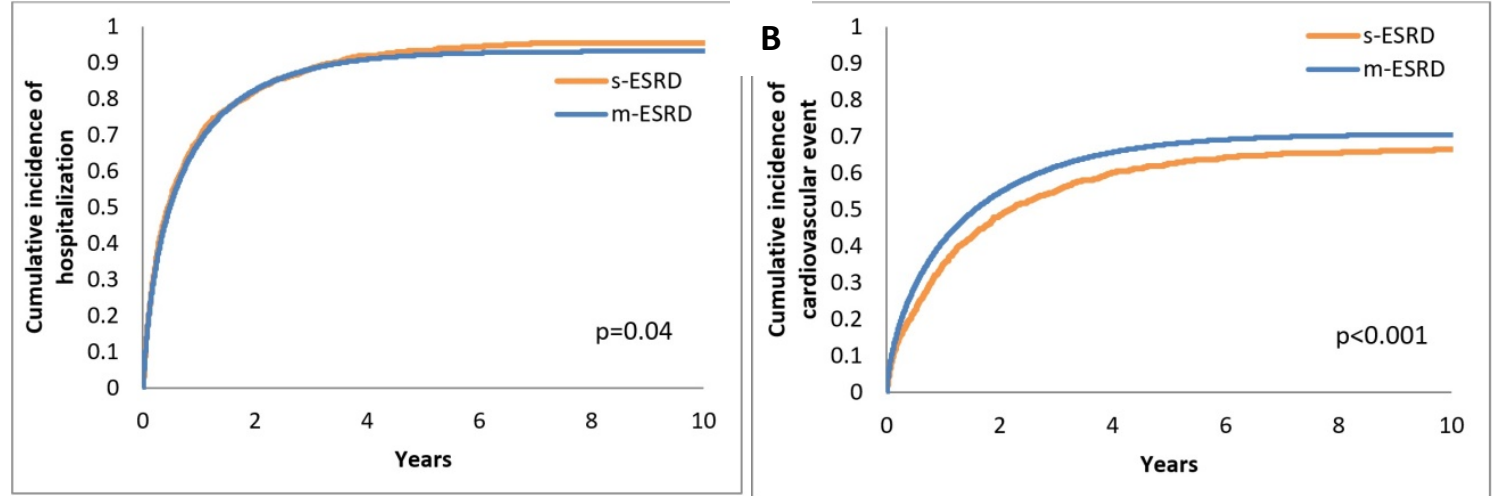

Number at risk

$\begin{array}{ccccccc}\text { Years } & 0 & 2 & 4 & 6 & 8 & 10 \\ - & 1635 & 223 & 57 & 16 & <11 & <11 \\ - & 310,964 & 36,531 & 7591 & 1674 & 375 & 88\end{array}$

C

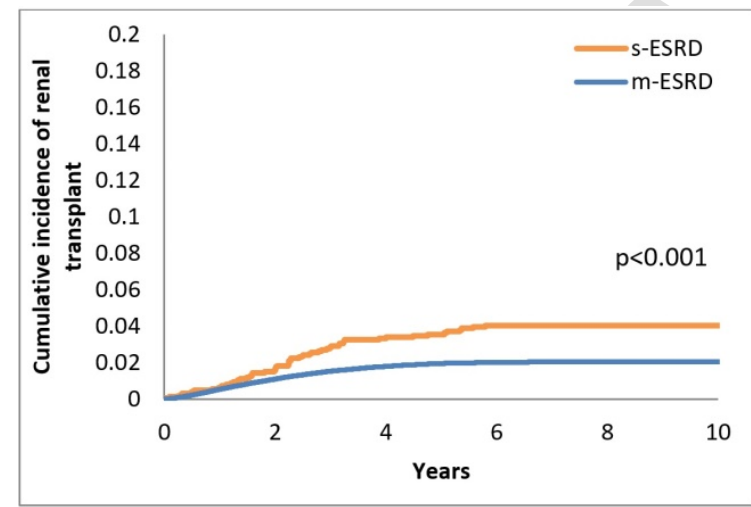

Number at risk

$\begin{array}{ccccccc}\text { Years } & 0 & 2 & 4 & 6 & 8 & 10 \\ - & 1635 & 915 & 436 & 173 & 61 & 17 \\ - & 310,964 & 153,233 & 64,798 & 24,073 & 7,618 & 2,013\end{array}$ 


\begin{tabular}{|c|c|c|}
\hline & $\begin{array}{c}\text { s-ESRD } \\
(n=1635)\end{array}$ & $\begin{array}{c}\text { m-ESRD } \\
(=310964)\end{array}$ \\
\hline Age at first ESRD service, mean (SD) & $74.4(5.7)$ & $75.9(6.5)$ \\
\hline $65-69$ & 394 (24.1\%) & 61973 (19.9\%) \\
\hline $70-74$ & $494(30.2 \%)$ & $79656(25.6 \%)$ \\
\hline $75-79$ & $429(26.2 \%)$ & 76735 (24.7\%) \\
\hline $80-84$ & 235 (14.4\%) & $58512(18.8 \%)$ \\
\hline 85 plus & $83(5.1 \%)$ & $34088(11.0 \%)$ \\
\hline \multicolumn{3}{|l|}{ Gender } \\
\hline Male & $1011(61.8 \%)$ & $159346(51.2 \%)$ \\
\hline Female & 624 (38.2\%) & $151566(48.7 \%)$ \\
\hline Missing & $0(0.0 \%)$ & $52(<0.1 \%)$ \\
\hline \multicolumn{3}{|l|}{ Race } \\
\hline Native American & $12(0.7 \%)$ & $2637(0.8 \%)$ \\
\hline Asian & $17(1.0 \%)$ & 11235 (3.6\%) \\
\hline Black & $271(16.6 \%)$ & 68221 (21.9\%) \\
\hline White & $1332(81.5 \%)$ & $227162(73.1 \%)$ \\
\hline Missing & $0(0.0 \%)$ & $26(<0.1 \%)$ \\
\hline Other & $<11(<0.7 \%)^{*}$ & $1683(0.5 \%)$ \\
\hline \multicolumn{3}{|l|}{ Charlson score } \\
\hline Median (range) & $8(1-15)$ & $7(0-17)$ \\
\hline \multicolumn{3}{|l|}{ Specific comorbidities } \\
\hline Myocardial infarction & $368(22.5 \%)$ & $81432(26.2 \%)$ \\
\hline Cerebrovascular disease & $555(33.9 \%)$ & $113047(36.4 \%)$ \\
\hline Diabetes & $934(57.1 \%)$ & $220933(71.0 \%)$ \\
\hline Diabetes with organ damage & $689(42.1 \%)$ & $178013(57.2 \%)$ \\
\hline History of hypertension & $1564(95.7 \%)$ & $295757(95.1 \%)$ \\
\hline Dyslipidemia & $963(58.9 \%)$ & $174618(56.2 \%)$ \\
\hline Other cancer & $542(33.1 \%)$ & $50332(16.2 \%)$ \\
\hline Kidney cancer & 1460 (89.3\%) & $10820(3.5 \%)$ \\
\hline
\end{tabular}

${ }^{*}$ Counts $<11$ suppressed as per USRDS policy. For all comparisons between s-ESRD vs. $\mathrm{m}-\mathrm{ESRD}$ groups, $\mathrm{p}<0.001$, except history of hypertension $(\mathrm{p}=0.31)$ and dyslipidemia $(p=0.03)$. m-ESRD: medically induced end-stage renal disease; s-ESRD: surgically induced end-stage renal disease. 


\begin{tabular}{|c|c|c|}
\hline \multirow{2}{*}{$\begin{array}{l}\text { Outcome } \\
\text { No competing risks }\end{array}$} & \multicolumn{2}{|c|}{$\begin{array}{c}\text { Multivariable-adjusted effect estimates for } \\
\text { s-ESRD vs. m-ESRD }\end{array}$} \\
\hline & HR (95\% CI) & $\mathbf{p}$ \\
\hline Overall survival & $0.76(0.72-0.80)$ & $<0.001$ \\
\hline Hospitalization risk $^{*}$ & $0.89(0.86-0.92)$ & $<0.001$ \\
\hline Competing risks analyses & $\begin{array}{l}\text { Sub-distributional } \\
\text { HR (95\% CI) }\end{array}$ & $\mathbf{p}$ \\
\hline Non-cancer mortality & $0.62(0.59-0.67)$ & $<0.001$ \\
\hline Cardiovascular event & $0.85(0.80-0.91)$ & $<0.001$ \\
\hline $\begin{array}{l}\text { Hospitalization (first } \\
\text { occurrence) }\end{array}$ & $0.99(0.94-1.04)$ & 0.77 \\
\hline Renal transplantation event & $1.63(1.26-2.10)$ & $<0.001$ \\
\hline
\end{tabular}

A Cox proportional hazards model was used to evaluate overall survival, a frailty model was used to evaluate hospitalization risk in a recurrent event analysis, and Fine-and-Grey competing risks models (sub-distributional) were used to evaluate time to non-cancer mortality, time to first cardiovascular events, time to first hospitalization, and time to transplant in the setting of competing risks. Multivariable models adjusted for age, race, Charlson comorbidity index, and history of myocardial infarction, cerebrovascular disease, diabetes, hypertension, and dyslipidemia. CI: confidence interval; HR: hazard ratio; m-ESRD: medically induced end-stage renal disease; s-ESRD: surgically induced end-stage renal disease. 
Supplementary Fig. 1. Study flow diagram. m-ESRD: medically induced end-stage renal disease; PCKD: polycystic kidney disease; s-ESRD: surgically induced end-stage renal disease;

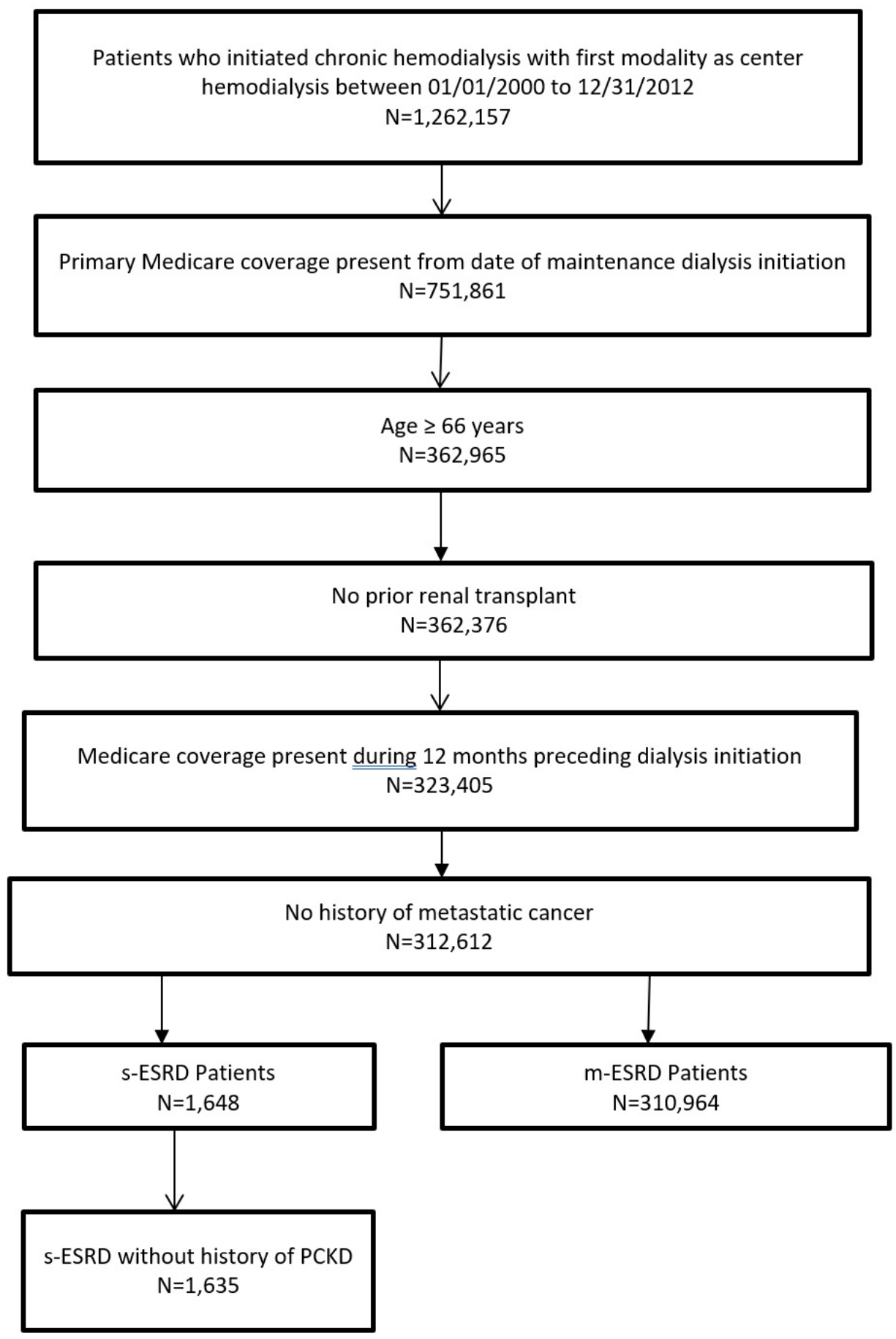




\begin{tabular}{|l|c|c|}
\hline $\begin{array}{l}\text { Supplementary Table 1. Sensitivity analysis excluding patients from the surgical } \\
\text { end-stage renal disease group with interval from surgery to dialysis greater than } \\
2 \text { months }\end{array}$ & $\begin{array}{r}\text { Multivariable-adjusted effect estimates for } \\
\text { s-ESRD vs. m-ESRD }\end{array}$ \\
\hline Outcome & HR (95\% CI) & p \\
\hline No competing risks & $0.74(0.70-0.80)$ & $<0.001$ \\
\hline Overall survival & $0.87(0.84-0.90)$ & $<0.001$ \\
\hline Hospitalization risk ${ }^{*}$ & $\begin{array}{c}\text { Sub-distributional } \\
\text { HR (95\% CI) }\end{array}$ & $<0.001$ \\
\hline Competing risks analyses & $0.60(0.55-0.65)$ & $<0.001$ \\
\hline Non-cancer mortality & $0.83(0.77-0.90)$ & 0.55 \\
\hline Cardiovascular event & $1.02(0.96-1.09)$ & 0.006 \\
\hline $\begin{array}{l}\text { Hospitalization (first } \\
\text { occurrence) }\end{array}$ & $1.56(1.14-2.14)$ & $\mathbf{p}$ \\
\hline Renal transplantation event &
\end{tabular}

A Cox proportional hazards model was used to evaluate overall survival, a frailty model was used to evaluate hospitalization risk in a recurrent event analysis, and Fine-and-Grey competing risks models (sub-distributional) were used to evaluate time to non-cancer mortality, time to first cardiovascular events, time to first hospitalization, and time to transplant in the setting of competing risks. Multivariable models adjusted for age, race, Charlson co-morbidity index, and history of myocardial infarction, cerebrovascular disease, diabetes, hypertension, and dyslipidemia. CI: confidence interval; HR: hazard ratio; m-ESRD: medically induced end-stage renal disease; s-ESRD: surgically induced end-stage renal disease. 


\section{Appendix. Diagnostic and procedure codes used}

\begin{tabular}{|c|c|}
\hline \multicolumn{2}{|c|}{ Diagnostic codes for renal or upper tract tumor/cancer } \\
\hline $\begin{array}{l}\text { ICD-9-CM } \\
\text { diagnostic codes } \\
\text { used }\end{array}$ & Description \\
\hline 189.0 & Malignant neoplasm of the kidney, except pelvis \\
\hline 223.0 & Benign neoplasm of kidney, except pelvis \\
\hline 189.1 & Malignant neoplasm of renal pelvis \\
\hline 189.2 & Malignant neoplasm of ureter \\
\hline \multicolumn{2}{|l|}{ Procedure codes } \\
\hline $\begin{array}{l}\text { ICD-9-CM } \\
\text { procedure codes } \\
\text { used }\end{array}$ & Description \\
\hline 55.4 & Partial nephrectomy \\
\hline 55.5 & Complete nephrectomy \\
\hline 55.51 & Nephroureterectomy \\
\hline 55.52 & Nephrectomy of remaining kidney \\
\hline 55.54 & Bilateral nephrectomy \\
\hline CPT codes & Description \\
\hline 50220 & $\begin{array}{l}\text { Nephrectomy, including partial ureterectomy, any open approach } \\
\text { including rib resection; }\end{array}$ \\
\hline 50225 & $\begin{array}{l}\text { Nephrectomy, including partial ureterectomy, any open approach } \\
\text { including rib resection; complicated because of previous surgery on } \\
\text { same kidney }\end{array}$ \\
\hline 50230 & $\begin{array}{l}\text { Nephrectomy, including partial ureterectomy, any open approach } \\
\text { including rib resection; radical, with regional lymphadenectomy and/or } \\
\text { vena caval thrombectomy }\end{array}$ \\
\hline 50234 & $\begin{array}{l}\text { Nephrectomy with total ureterectomy and bladder cuff; through same } \\
\text { incision }\end{array}$ \\
\hline 50236 & $\begin{array}{l}\text { Nephrectomy with total ureterectomy and bladder cuff; through } \\
\text { separate incision }\end{array}$ \\
\hline 50240 & Nephrectomy, partial \\
\hline 50543 & Laparoscopy, surgical; partial nephrectomy \\
\hline 50545 & $\begin{array}{l}\text { Laparoscopy, surgical; radical nephrectomy (includes removal of } \\
\text { Gerota’s fascia and surrounding fatty tissue, removal of regional lymph } \\
\text { nodes, and adrenalectomy) }\end{array}$ \\
\hline
\end{tabular}




\begin{tabular}{|l|l|}
\hline 50546 & \multicolumn{1}{|l|}{ Laparoscopy, surgical; nephrectomy, including partial ureterectomy } \\
\hline 50548 & \multicolumn{1}{|l|}{ Laparoscopy, surgical; nephrectomy with total ureterectomy } \\
\hline ICD-9 codes for cardiac event outcomes \\
\hline ICD-9 & Code descriptions \\
\hline Myocardial infarction \\
\hline 410 & ACUTE MYOCARDIAL INFARCTION \\
\hline 410.0 & ACUTE MYOCARDIAL INFARCTION OF ANTEROLATERAL WALL \\
\hline 410.00 & $\begin{array}{l}\text { ACUTE MYOCARDIAL INFARCTION OF ANTERIOLATERAL WALL, } \\
\text { EPISODE OF CARE UNSPECIFIED }\end{array}$ \\
\hline 410.01 & $\begin{array}{l}\text { ACUTE MYOCARDIAL INFARCTION OF ANTERIOLATERAL WALL, } \\
\text { INITIAL EPISODE OF CARE }\end{array}$ \\
\hline 410.02 & $\begin{array}{l}\text { ACUTE MYOCARDIAL INFARCTION OF ANTERIOLATERAL WALL, } \\
\text { SUBSEQUENT EPISODE OF CARE }\end{array}$ \\
\hline 410.1 & ACUTE MYOCARDIAL INFARCTION OF OTHER ANTERIOR WALL \\
\hline 410.10 & $\begin{array}{l}\text { ACUTE MYOCARDIAL INFARCTION OF OTHER ANTERIOR WALL, } \\
\text { EPISODE OF CARE UNSPECIFIED }\end{array}$ \\
\hline 410.11 & $\begin{array}{l}\text { ACUTE MYOCARDIAL INFARCTION OF OTHER ANTERIOR WALL, INITIAL } \\
\text { EPISODE OF CARE }\end{array}$ \\
\hline 410.12 & $\begin{array}{l}\text { ACUTE MYOCARDIAL INFARCTION OF OTHER ANTERIOR WALL, } \\
\text { SUBSEQUENT EPISODE OF CARE }\end{array}$ \\
\hline 410.2 & ACUTE MYOCARDIAL INFARCTION OF INFEROLATERAL WALL \\
\hline 410.20 & $\begin{array}{l}\text { ACUTE MYOCARDIAL INFARCTION OF INFEROLATERAL WALL, EPISODE } \\
\text { OF CARE UNSPECIFIED }\end{array}$ \\
\hline 410.21 & ACUTE MYOCARDIAL INFARCTION OF INFEROLATERAL WALL, INITIAL \\
\hline 410.22 & $\begin{array}{l}\text { ACUTE MYOCARDIAL INFARCTION OF INFEROLATERAL WALL, } \\
\text { SUBSEQUENT EPISODE OF CARE }\end{array}$ \\
\hline 410.3 & ACUTE MYOCARDIAL INFARCTION OF INFEROPOSTERIOR WALL \\
\hline 410.30 & $\begin{array}{l}\text { ACUTE MYOCARDIAL INFARCTION OF INFEROPOSTERIOR WALL, } \\
\text { EPISODE OF CARE UNSPECIFIED }\end{array}$ \\
\hline 410.31 & $\begin{array}{l}\text { ACUTE MYOCARDIAL INFARCTION OF INFEROPOSTERIOR WALL, } \\
\text { INITIAL EPISODE OF CARE }\end{array}$ \\
\hline 410.32 & $\begin{array}{l}\text { ACUTE MYOCARDIAL INFARCTION OF INFEROPOSTERIOR WALL, } \\
\text { SUBSEQUENT OF EPISODE OF CARE }\end{array}$ \\
\hline 410.4 & ACUTE MYOCARDIAL INFARCTION OF OTHER INFERIOR WALL \\
\hline 410.41 & ACUTE MYOCARDIAL INFARCTION OF OTHER INFERIOR WALL, EPISODE \\
\hline
\end{tabular}




\begin{tabular}{|l|l|}
\hline & EPISODE OF CARE \\
\hline 410.42 & $\begin{array}{l}\text { ACUTE MYOCARDIAL INFARCTION OF OTHER INFERIOR WALL, } \\
\text { SUBSEQUENT EPISODE OF CARE }\end{array}$ \\
\hline 410.5 & ACUTE MYOCARDIAL INFARCTION OF OTHER LATERAL WALL \\
\hline 410.50 & $\begin{array}{l}\text { ACUTE MYOCARDIAL INFARCTION OF OTHER LATERAL WALL, EPISODE } \\
\text { OF CARE UNSPECIFIED }\end{array}$ \\
\hline 410.51 & $\begin{array}{l}\text { ACUTE MYOCARDIAL INFARCTION OF OTHER LATERAL WALL, INITIAL } \\
\text { EPISODE OF CARE }\end{array}$ \\
\hline 410.52 & $\begin{array}{l}\text { ACUTE MYOCARDIAL INFARCTION OF OTHER LATERAL WALL, } \\
\text { SUBSEQUENT EPISODE OF CARE }\end{array}$ \\
\hline 410.6 & TRUE POSTERIOR WALL INFARCTION \\
\hline 410.60 & $\begin{array}{l}\text { ACUTE MYOCARDIAL INFARCTION OF TRUE POSTERIOR WALL, EPISODE } \\
\text { OF CARE UNSPECIFIED }\end{array}$ \\
\hline 410.61 & $\begin{array}{l}\text { ACUTE MYOCARDIAL INFARCTION OF TRUE POSTERIOR WALL, INITIAL } \\
\text { EPISODE OF CARE }\end{array}$ \\
\hline 410.62 & $\begin{array}{l}\text { ACUTE MYOCARDIAL INFARCTION OF TRUE POSTERIOR WALL, } \\
\text { SUBSEQUENT EPISODE OF CARE }\end{array}$ \\
\hline 410.7 & SUBENDOCARDIAL INFARCTION \\
\hline 410.70 & $\begin{array}{l}\text { ACUTE SUBENDOCARDIAL INFARCTION, EPISODE OF CARE } \\
\text { UNSPECIFIED }\end{array}$ \\
\hline 410.71 & ACUTE SUBENDOCARDIAL INFARCTION, INITIAL EPISODE OF CARE \\
\hline 410.72 & $\begin{array}{l}\text { ACUTE SUBENDOCARDIAL INFARCTION, SUBSEQUENT EPISODE OF } \\
\text { CARE }\end{array}$ \\
\hline 410.8 & ACUTE MYOCARDIAL INFARCTION OF OTHER SPECIFIED SITES \\
\hline 410.80 & $\begin{array}{l}\text { ACUTE MYOCARDIAL INFARCTION OF OTHER SPECIFIED SITES, EPISODE } \\
\text { OF CARE UNSPECIFIED }\end{array}$ \\
\hline 410.81 & $\begin{array}{l}\text { ACUTE MYOCARDIAL INFARCTION OF OTHER SPECIFIED SITES, INITIAL } \\
\text { EPISODE OF CARE }\end{array}$ \\
\hline 410.82 & $\begin{array}{l}\text { ACUTE MYOCARDIAL INFARCTION OF OTHER SPECIFIED SITES, } \\
\text { SUBSEQUENT EPISODE OF CARE }\end{array}$ \\
\hline 410.9 & ACUTE MYOCARDIAL INFARCTION OF UNSPECIFIED SITE \\
\hline 410.90 & $\begin{array}{l}\text { ACUTE MYOCARDIAL INFARCTION OF UNSPECIFIED SITE, EPISODE OF } \\
\text { CARE UNSPECIFIED }\end{array}$ \\
\hline 410.91 & $\begin{array}{l}\text { ACUTE MYOCARDIAL INFARCTION OF UNSPECIFIED SITE, INITIAL } \\
\text { EPISODE OF CARE }\end{array}$ \\
\hline 410.92 & \begin{tabular}{l} 
EPISODE OF CARE \\
\hline
\end{tabular} \\
\hline
\end{tabular}




\begin{tabular}{|l|l|}
\hline 430 & SUBARACHNOID HEMORRHAGE \\
\hline 431 & INTRACEREBRAL HEMORRHAGE \\
\hline 432 & OTHER AND UNSPECIFIED INTRACRANIAL HEMORRHAGE \\
\hline 432.0 & NONTRAUMATIC EXTRADURAL HEMORRHAGE \\
\hline 432.1 & SUBDURAL HEMORRHAGE \\
\hline 432.9 & UNSPECIFIED INTRACRANIAL HEMORRHAGE \\
\hline Ischemic CVA \\
\hline 433 & OCCLUSION AND STENOSIS OF PRECEREBRAL ARTERIES \\
\hline 433.0 & OCCLUSION AND STENOSIS OF BASILAR ARTERY \\
\hline 433.00 & $\begin{array}{l}\text { OCCLUSION AND STENOSIS OF BASILAR ARTERY, WITHOUT MENTION } \\
\text { OF CEREBRAL INFARCTION }\end{array}$ \\
\hline 433.01 & $\begin{array}{l}\text { OCCLUSION AND STENOSIS OF BASILAR ARTERY, WITH CEREBRAL } \\
\text { INFARCTION }\end{array}$ \\
\hline 433.1 & OCCLUSION AND STENOSIS OF CAROTID ARTERY \\
\hline 433.10 & OCCLUSION AND STENOSIS OF CAROTID ARTERY \\
\hline 433.11 & $\begin{array}{l}\text { OCCLUSION AND STENOSIS OF CAROTID ARTERY, WITH CEREBRAL } \\
\text { INFARCTION }\end{array}$ \\
\hline 433.2 & OCCLUSION AND STENOSIS OF VERTEBRAL ARTERY \\
\hline 433.20 & $\begin{array}{l}\text { OCCLUSION AND STENOSIS OF VERTEBRAL ARTERY, WITHOUT } \\
\text { MENTION OF CEREBRAL INFARCTION }\end{array}$ \\
\hline 433.21 & $\begin{array}{l}\text { OCCLUSION AND STENOSIS OF VERTEBRAL ARTERY, WITH CEREBRAL } \\
\text { INFARCTION }\end{array}$ \\
\hline 433.3 & $\begin{array}{l}\text { OCCLUSION AND STENOSIS OF MULTIPLE AND BILATERAL } \\
\text { PRECEREBRAL ARTERIES }\end{array}$ \\
\hline 433.30 & OCCLUSION AND STENOSIS OF MULTIPLE AND BILATERAL ARTERIES, \\
WITHOUT MENTION OF CEREBRAL INFARCTION
\end{tabular}




\begin{tabular}{|l|l|}
\hline & WITH CEREBRAL INFARCTION \\
\hline 434 & OCCLUSION OF CEREBRAL ARTERIES \\
\hline 434.0 & CEREBRAL THROMBOSIS \\
\hline 434.00 & $\begin{array}{l}\text { CEREBRAL THROMBOSIS WITHOUT MENTION OF CEREBRAL } \\
\text { INFARCTION }\end{array}$ \\
\hline 434.01 & CEREBRAL THROMBOSIS WITH CEREBRAL INFARCTION \\
\hline 434.1 & CEREBRAL EMBOLISM \\
\hline 434.10 & CEREBRAL EMBOLISM WITHOUT MENTION OF CEREBRAL INFARCTION \\
\hline 434.11 & CEREBRAL EMBOLISM WITH CEREBRAL INFARCTION \\
\hline 434.9 & CEREBRAL ARTERY OCCLUSION, UNSPECIFIED \\
\hline 434.90 & $\begin{array}{l}\text { CEREBRAL ATERY OCCLUSION, UNSPECIFIED, WITHOUT MENTION OF } \\
\text { CEREBRAL INFARCTS }\end{array}$ \\
\hline 434.91 & $\begin{array}{l}\text { CEREBRAL ARTERY OCCLUSION, UNSPECIFIED, WITH CEREBRAL } \\
\text { INFARCTION }\end{array}$ \\
\hline 435 & TRANSIENT CEREBRAL ISCHEMIA \\
\hline 435.0 & BASILAR ARTERY SYNDROME \\
\hline 435.1 & VERTEBRAL ARTERY SYNDROME \\
\hline 435.2 & SUBCLAVIAN STEAL SYNDROME \\
\hline 435.3 & VERTEBROBASILAR ARTERY SYNDROME \\
\hline 435.8 & OTHER SPECIFIED TRANSIENT CEREBRAL ISCHEMIAS \\
\hline 435.9 & UNSPECIFIED TRANSIENT CEREBRAL ISCHEMIA \\
\hline 436 & ACUTE, BUT ILL-DEFINED, CEREBROVASCULAR DISEASE \\
\hline Sudden cardiac death \\
\hline 427.5 & CARDIAC ARREST \\
\hline
\end{tabular}

